\title{
Educação Intercultural, Epistemologias E Projetos Educativos
}

\author{
Vera lúcia Chacon Valença \\ Universidade do Sul de Santa Catarina (Unisul), Tubarão, \\ Santa Catarina, Brasil \\ LUCIANE Pandini Simiano \\ Universidade do Sul de Santa Catarina (Unisul), Tubarão, \\ Santa Catarina, Brasil \\ Amanda da Silva Menger \\ Universidade do Sul de Santa Catarina (Unisul), Tubarão, \\ Santa Catarina, Brasil
}

\begin{abstract}
RESUMO: Este artigo, realizado a partir de uma revisão teórica, tem por propósito apresentar algumas contribuições que podem auxiliar na elaboração de projetos educativos na perspectiva da educação intercultural. Objetiva-se o favorecimento da integração dialética de pessoas que apresentam diferenças e que pertencem a contextos socioeconômicos diversos. Nessa perspectiva são valorizadas a circulação de saberes e as epistemologias "hibridizadas", assim como o enfrentamento político para modificar algumas relações de poder, visando a promover a "emancipação" infantil. Esta, apoiada numa postura consciente-crítica-ética, culminaria com uma re-novação nas relações, com base nos diálogos e nas novas formas de participação e expressão do ser, viver e saber da infância, que devem estar presentes nos projetos educativos.

Palavras-chave: Educação Intercultural. Emancipação. Projetos Educativos.
\end{abstract}


INTRODUÇÃO

Vários estudos e pesquisas vêm subsidiando os projetos educativos elaborados e desenvolvidos pelos educadores, mas com relação à abordagem intercultural visando à educação infantil, ainda há muito a ser realizado. Quando se fala em emancipar a infância, também se pode, por analogia ao que se escreve sobre a decolonialidade entre países e culturas, mencionar uma espécie de decolonialidade referente à liberação das crianças no que diz respeito à sua subordinação aos adultos.

A abordagem intercultural na educação infantil também se justifica no sentido de preservar e proteger a infância quanto a uma subordinação excessiva a que alguns adultos a submetem. Isso exige uma postura crítica por parte dos educadores no sentido de tentar minimizar os efeitos negativos dessa subordinação que muitas vezes asfixiam as crianças. Além disso, é também necessário ampliar as relações entre crianças de diversas etnias e contextos sociais, pois algumas delas ficam limitadas às relações desenvolvidas em verdadeiros "guetos étnicos". Nesse sentido, acredita-se, é também possível pensar na alternativa de criar projetos educativos nos quais elas possam participar de modo mais efetivo, projetos que contemplem o ser/ viver/saber das crianças e assim contribuir para a decolonialidade/emancipação da infância como grupo minoritário. Coloca-se então a necessidade imperativa de uma abordagem crítica da interculturalidade que, de acordo com Catherine Walsh, pode partir

do problema estrutural-colonial-racial, isto é, de um reconhecimento de que a diferença se constrói dentro de uma estrutura e matriz colonial de poder radicalizado e hierarquizado, com os brancos e branqueadores em cima e os povos indígenas e afrodescendentes nos andares inferiores" (2009, p. 3).

Nessa direção, a interculturalidade passa a ser "uma ferramenta, como um processo e projeto que se constrói a partir das gentes - e como demanda da subalternidade -, em contraste à interculturalidade funcional que identifica o problema da diversidade ou diferença em si" (WALSH, 2009, p. 3). Para a autora, o respeito às diferenças deve anteceder à elaboração dos projetos que se interessam em unir e integrar as pessoas, inclusive crianças, 
sem descaracterizá-las. Tal trabalho reside num grande desafio para o qual é necessário, além de uma opção pessoal-política, uma formação teórica consistente, razão que leva a ser pensada a formação continuada dos educadores.

Entende-se, então, que trabalhar na perspectiva sugerida por Walsh é ainda mais difícil em contextos culturais mais rígidos, nos espaços onde existem "guetos", onde o "diferente" é considerado "um estranho no ninho", onde a alteridade do outro é sufocada, asfixiada. E isso ocorre também nas relações de subordinação de crianças a adultos, o que alerta para a necessidade de realizar uma "decolonialidade" dessa parte da população, a infância.

Por decolonialidade, Walsh (2009) compreende os processos de interculturalização de via múltipla, que não partem da "etnicidade em si, mas de uma subjetividade e um lócus de enunciação definidos por e construídos na experiência de subalternização social, política e cultural de grupos, porém também de conhecimentos" (2009, p. 10). Sabe-se que esse viés epistemológico, defendido pela autora supramencionada, remete ao status social das crianças que, de acordo com Suzanne Mollo-Bouvier, leva os sociólogos a se confrontarem com uma dupla questão: "considerar o lugar e o papel das crianças na estruturação e transformações do campo social; construir os paradigmas de uma sociologia da infância" (2006, p. 37).

Neste texto, abordar-se-á a primeira questão levantada por Mollo-Bouvier, para o que se utiliza, como referência, as epistemologias "híbridas". Esta expressão refere-se àquelas epistemologias que valorizam os saberes, não somente os saídos de pesquisas científicas, mas também aqueles decorrentes de conhecimentos populares. Corresponde ao que Santos e Meneses (2010) denominam de Epistemologias do Sul. Tais autores não descartam as epistemologias hegemônicas, as do norte, porém sugerem que não se desperdicem as experiências populares, atentando para o valor dos conhecimentos e aprendizagens pelo cotidiano.

No entanto, quando Santos e Meneses propõem aprender com o Sul, eles entendem o Sul como "uma metáfora do sofrimento humano causado pelo capitalismo, significa precisamente o objectivo de reinventar a emancipação social indo mais além da teoria crítica produzida no Norte e da práxis social e política que ela subscreverá" (SANTOS; MENESES, 2010, p. 06). 
Santos (1997), em artigo escrito sobre os Direitos Humanos, e visando à emancipação dos sujeitos, aponta para as condições de uma interculturalidade progressista que pressupõe a elevação do diálogo intercultural "até um nível suficientemente alto para minimizar a possibilidade de conquista cultural, mas não tão alto que destrua a própria possibilidade de diálogo" (SANTOS, 1997, p. 13). E, a fim de alcançar esse objetivo, os direitos humanos servem de roteiro emancipador.

Para compreender a situação intercultural na direção progressista, o autor sugere o uso da hermenêutica diatópica, que ele entende como "a ideia de que topoi de uma dada cultura por mais fortes que sejam, são tão incompletos quanto à própria cultura a que pertencem" (SANTOS, 1997, p. 15). O termo topoi é compreendido como lugares comuns retóricos mais abrangentes de determinada cultura. Os topoi funcionariam como premissas de argumentação - "que por sua evidência não se discutem e tornam possíveis a produção e a troca de argumentos" (1997, p. 15).

\section{SOBRE EDUCAÇÃO, APRENDIZAGEM E CULTURA}

Inúmeros são os conceitos de educação, de aprendizagem e de cultura. Num livro, recentemente lançado no Brasil, Mialaret (2013) apresenta uma revisão a respeito do que vem a ser educação. Ele menciona as várias possibilidades de conceituar o termo. Assim, educação:

a) evoca uma instituição social, que possui estruturas de funcionamento, apresentando algumas delas sistemas mais ou menos difusos, alguns dos quais completam a função dos ministérios de Educação, quais sejam: formação de adultos, animações culturais. Envolve também sistemas informais, tais como rádio, televisão, internet, etc.;

b) significa o resultado de uma ação, ou seja, os produtos dela resultantes, por exemplo: educação popular, oposta à erudita;

c) está associado a um determinado conteúdo;

d) diz respeito ao processo resultante da comunicação entre seres humanos e que envolve trocas e modificações recíprocas decorrentes das relações estabelecidas entre eles (MIALARET, 2013, p. 24).

É sobre esse último significado que recai o interesse neste texto. É também nessa perspectiva que Montandon (1997) utiliza a expressão "edu- 
cação-socialização". Ela considera que a educação faz parte da socialização, estando ela, "sobretudo associada a um projeto, a socialização compreende aprendizagens que se produzem além do projeto, sem que ela tenha tido aprendizagens intencionais" (MONTANDON, 1997, p. 17). A fronteira entre os dois processos é muito tênue, sendo, às vezes, difícil distingui-los. Quando a educação se refere à primeira infância, Eduards (1999) ressalta que ela

envolve a interação complexa com múltiplas pessoas (crianças, pais, colegas, governo, público) e estimulação da aprendizagem e desenvolvimento das crianças através da concepção de uma organização escolar ótima, dos ambientes físicos, do currículo e da pedagogia (1999, p. 174).

A aprendizagem é também noção central da teoria de Rogoff (2012, p. 318), para quem "aprender é participar". A aprendizagem irá "depender do modelo de criança que se tem, e não está apenas ligada à atividade escolar e aos exames. Aprende-se também por meio da observação e da atividade conjunta" (BROUGÈRE; ULMANN, 2012, p. 320). A importância da interação com o outro, enfatizada por Bussoletti e Molon (2010), é um princípio constitutivo do sujeito. Seria através da interação que "se recupera e se explica a singularidade e a totalidade, a unicidade do sujeito, a unidade do mundo no particular, se compreende a totalidade nas múltiplas vozes que participam do diálogo da vida" (BUSOLETTI; MOLON, 2010, p. 87).

Teria sido facilitada a participação da criança no diálogo? Haveria possibilidade de interação num mundo que apresentaria, segundo Canclini (2003), uma "globalização imaginada" na medida em que não há uma "co-presença e interação de todos os países, de todas as empresas e todos os consumidores" (2003, p. 11). Ao contrário, conforme ainda Canclini, o que existe de fato é "um processo segmentado e desigual" (2003, p. 167) e não de uma globalização efetiva. Se os países não ocupam o mesmo status, como interagir?

Outra questão pode ser lembrada: e se a interação envolver o"outro-criança"? Ter-se-á de lembrar que além da diversidade há também que ser considerada a diferença. E mais ainda: há de se pensar na sua condição de subordinação aos adultos. Então, o outro-criança apresenta uma particularidade grande com relação aos adultos e estes podem sufocar sua alteridade e 
abafar sua autonomia. Esta não significa ruptura, mas certo nível de liberação das crianças nas suas relações com os educadores. Entende-se, além disso, que considerar a existência de um indivíduo não deve representar a exclusão do componente social como um dos determinantes desse mesmo indivíduo.

Compreende-se que o protagonismo infantil, possibilitado inclusive pelo respeito às diferenças e desejo de diálogo entre adultos e crianças, não deve significar a coroação da criança centrada nela mesma, desprovida de uma percepção atenta ao meio onde vive e às pessoas com quem convive. Por isso defende-se o estabelecimento de um contrato pedagógico entre pessoas que ocupam, hierarquicamente, lugares diferentes, sendo todas elas sujeitos, explicitando a diversidade e contribuindo para a história da humanidade. Nesse sentido, educar não é só "ensinar e ensinar não é transferir conhecimento, mas criar possibilidades para a sua produção ou a sua construção" (FREIRE, 2014, p. 24). Isso exige, naturalmente, reforçar nos educandos "a capacidade crítica, sua curiosidade, sua insubmissão" (2014, p. 28).

O processo pedagógico deveria, então, "transformar os educandos em reais sujeitos de construção e da reconstrução do saber ensinado, ao lado do educador, igualmente sujeito do processo" (FREIRE, 2014, p. 28), o que em princípio poderá ser estimulado pelas pedagogias progressistas, únicas capazes de absorver as crianças como protagonistas.

Nesse contexto, menciona-se Ottavi (2006), que lembra que, ao se propor às crianças e adolescentes que sejam "eles mesmos", não se pode esquecer que o desenvolvimento individual é associado à "dimensão da experiência coletiva, com sua inscrição tanto na natureza quanto na história" (OTTAVI, 2006, p. 111). Se Ottavi faz uma abordagem do desenvolvimento pessoal, Freire (2014), utilizando uma perspectiva política, lembra: "a natureza que a ontologia cuida, se gesta socialmente na história" (2014, p. 20). Para Freire, a natureza do ser humano, inconclusa, necessita de uma educação "como processo permanente", e a inserção do educando na sociedade caracteriza-se por um "permanente movimento de procura, que rediscute a curiosidade ingênua e a crítica, virando epistemologia" (2014, p. 15-16). Finalmente, ele alerta para o fato de que "ensinar exige respeito à autonomia do educando", enfatizando que o "respeito é um imperativo ético" (FREIRE, 
2014, p. 58). Mas, afinal, é possível considerar a criança como ser autônomo-participativo- protagonista?

A CRIANÇA PROTAGONISTA: ALGUNS CONTRIBUTOS

As pesquisas sobre as crianças definiram-nas como seres especiais e complexos. Para entendê-las seria necessária a realização de pesquisas interdisciplinares, tarefa difícil a ser concretizada. Porém, alguns argumentos da psicologia, sociologia, filosofia, entre outros, ajudam a desvendá-las.

As crianças são ativas, criativas, reflexivas e dinâmicas, isso não é novidade. Os trabalhos de psicólogos do desenvolvimento, tais como Piaget, Vigotski e Freud, entre outros, o demonstraram. Eles evidenciaram as especificidades de sua evolução e as particularidades dos seus comportamentos, comparando-os aos dos adultos. Chamaram atenção para o modo como elas representam o mundo, a importância das interações sociais na sua evolução, a indissolubilidade entre cognição e afeto, assim como também discutiram a elaboração pessoal que elas realizam sobre as aprendizagens. Afirmaram que a influência dos contextos sociais é fundamental no desenvolvimento. Os psicanalistas, sobretudo, alertaram para a importância das relações afetivas na estruturação da personalidade.

Os psicólogos do desenvolvimento possibilitaram, finalmente, entre outros, a compreensão da conquista do mundo pela criança, explicando inclusive a sua evolução gradativa no que diz respeito à conquista da autonomia, sem o que não se poderia falar de um "sujeito participativo", podendo assumir o protagonismo de sua história pessoal e fazer parte ativa da construção da sociedade. Os estudos psicogenéticos, naturalmente, realizam abordagens diferentes: se alguns teóricos dão maior peso à autonomia, e que, em consequência, porque a criança existe como sujeito, passa a ter a possibilidade de ser participativa, outros irão ressaltar o contrário: que pelo fato de terem participado, interagido com os outros, elas se desenvolverão, tornando-se autônomas.

Contudo, neste texto, fundamentou-se no reconhecimento da criança como sujeito de direitos, ativo no processo de construção histórica. Essa concepção implica pensar outra forma de pesquisar, construir conhecimento 
e elaborar propostas educativas para e com elas. Não cabendo compreender as crianças e suas infâncias sob um ângulo de análise adultocêntrico, mas a partir da lógica infantil.

O desafio que se apresenta é aprender a olhar para as crianças sob uma nova perspectiva, não reduzindo a sua capacidade de participação, comunicação e expressão somente à fala, mas de estar atentos a movimentos, olhares, gestos, sons, silêncios e várias outras linguagens. Isso implica compreendê-las para:

[...] além das figuras retóricas, com intenção de falar dela consentindo a resposta, permitindo uma comunicação não só no verbo, mas também no gesto e no signo, no movimento e no caminho, no silêncio e no sintoma, e dando espaço e direito a tais linguagens. Para tanto é necessário abandonar uma técnica da palavra aculturante na qual se enreda a infância, e passar ao exercício de um ouvido refinado, uma perspectiva de mútua construção - adultos e não adultos - de competências expressivas e comunicativas em que o registro não seja o da vigilância e da captura, mas o da recíproca distribuição e da troca, do reconhecimento das mensagens e indícios expressivos em códigos muito variados, da legitimação dos sons e das pausas porque dotados de qualidade informativa (BONDIOLI; BECCHI, 1994, p. 83).

Na perspectiva da participação, é necessário desenvolver novas relações entre adulto e criança, não a reconhecendo mais como um "vir a ser", mas como alguém que precisa ser valorado, considerando-a como coparticipante da sua construção da sociedade. É possível que a compreensão das crianças a partir dos autores supracitados traga repercussões para a compreensão dos adultos sobre questões fundamentais da prática pedagógica, inclusive de viés intercultural.

\section{CONTRIBUTOS À COMPREENSÃO DA EDUCAÇÃO INTERCULTURAL}

Os conceitos sobre interculturalidade e educação intercultural foram sendo alterados com o passar dos anos. Coppete, Fleuri e Stoltz (2012) apresentam um resumo retrospectivo a esse respeito no artigo: Educação para a diversidade numa perspectiva intercultural. Eles lembram que culturas diferentes "são entendidas como contextos complexos e a relação entre elas produz confrontos entre visões do mundo diferentes" (2012, p. 232). Então 
a educação deveria ter por objetivo a criação de um projeto comum que visasse, a partir de uma abordagem dialética, a integrar as diferenças. Tal projeto teria como suporte a articulação entre políticas de identidade e de igualdade, e, naturalmente, tudo isso teria repercussões sobre os projetos pedagógicos. Afirmam os autores que "a diferença e a identidade cultural são candentes para a educação, principalmente no âmbito das escolas e, por conseguinte, das práticas pedagógicas" (2012, p. 236). De acordo com Paola Falteri, o termo intercultura

aponta para um projeto que, no plano educacional, pretende intervir nas mudanças induzidas pelo contato com as diversidades, de modo a promover atitudes abertas ao confronto e conduzir os processos aculturadores a uma integração entre culturas que não colonializem as minorias (1998, p. 37).

Ressaltando a importância da convivência, Paola Falteri chama a atenção para o fato de que só se pode falar de intercultura "quando se criam as condições para a troca, quando se estabelece uma relação de reciprocidade, quando, no reconhecer o'outro', nos tornamos conscientes de nossa própria cultura" (1998, p. 39, grifo da autora). E para superar isso é necessário, segundo ela, "criar oportunidades de interação", mas ir além: trocar com o outro, fazer com ele, produzir junto. Quais as estratégias que facilitariam as interações? A partir de quais recursos pedagógicos elas poderiam ser potencializadas?

Paola Falteri refere que a escola é um espaço onde essa atitude pode ser fomentada desde cedo. Apresenta também o exemplo do Movimento de Cooperação Educativa (MCE), que é uma associação italiana inspirada em Célestin Freinet. Projetos de cooperação educativa envolvendo adultos e crianças, e entre crianças de mais de um país, são estratégias também apontadas por Falteri no sentido de aproximar as pessoas, dando maior atenção educativa à diversidade, "produzindo um patrimônio educativo e uma orientação educativa voltada para interação com a diferença. E isso tudo tendo por base os seguintes elementos: a pedagogia popular; a dialética identidade/ diferença; e a pedagogia do ouvir" (FALTERI, 1998).

Mas é também necessário, como explica Canclini (1998), investir nas comunicações via rede que podem auxiliar a criação de projetos educativos compatíveis com o desejo de possibilitar trocas mais profundas. Canclini 
(1998) sugere a utilização de políticas que ressaltem a economia cultural do mercado, a saída da oposição entre o local e o global, e a realização de articulações "entre o concreto e o abstrato, entre o imediato e o intercultural" (CANCLINI, 2003, p. 27). Seria necessário encarar "a heterogeneidade, a diferença e a desigualdade - o que se pode realizar e ser com os outros" (2003, p. 28). O debate sobre a questão da identidade deveria ser deslocado para a dos desencontros entre políticas de integração supranacional e comportamentos cidadãos. Pergunta-se o autor: "Seria possível instituir sujeitos em estruturas sociais ampliadas?" (2003, p. 28). Para Canclini, sim. Isso porque "os atores sociais podem estabelecer novas interconexões entre culturas e circuitos que potencializam as iniciativas sociais" (2003, p. 28). Conforme o referido autor, um instrumento que poderia facilitar as interconexões são as redes culturais que se dedicam à "negociação da diversidade" (2003, p. 29).

De acordo com Copette, a interculturalidade é um "um processo dinâmico marcado pela intercessão de perspectivas que podem ser entendidas como representações sociais produzidas em interação" (2012, p. 341). Baseados em Walsh (2009), Fleuri, Coppete e Azibeiro (2009) lembram que a interculturalidade pode ser estudada sob três perspectivas: relacional, funcional e crítica. A relacional evidencia os contatos e intercâmbios entre culturas diferentes. Assim, as reações interculturais são reduzidas "às relações individuais sem considerar os contextos sociopolíticos de subalternização (COPPETE; FLEURI; STOLTZ, 2012, p. 243). A perspectiva funcional, assim denominada por Walsh, "reconhece a diferença cultural com o objetivo de incluí-la na estrutura social estabelecida" (COPPETE; FLEURI; STOLTZ, 2012, p. 243). Os autores da abordagem funcional destacam a importância do diálogo, da convivência e da tolerância apresentando, contudo, um limite: não questionam as desigualdades sociais. Walsh, propondo a abordagem crítica, enfatiza a necessidade de considerar o

problema estrutural-colonial-racial. Isto é, de um reconhecimento de que a diferença se constrói dentro de uma estrutura e matriz colonial de poder racializado e hierarquizado, com os brancos e branqueados em cima e os povos indígenas e afrodescendentes nos andares inferiores. A partir desta posição, a interculturalidade passa a ser entendida como uma ferramenta, como um processo e projeto que se constrói a partir das gentes - e como 
demanda da subalternidade - em contraste à funcional, que se exerce a partir de cima. Aponta e requer a transformação das estruturas, instituições e relações sociais, e a construção de condições de estar, ser, conhecer, aprender, sentir e viver distintas (2009, p. 03).

Nesse sentido, admite-se a inclusão da infância como parte da população a ser contemplada pelos projetos políticos e de sociedade, nos quais as crianças podem ser consideradas, pelas representações sobre elas atualmente vigentes, como participantes e coautoras da cultura. Retoma-se então a proposta de Walsh, para quem não é suficiente utilizar a interculturalidade funcional - mencionada inclusive por Canclini, mas utilizar outro parâmetro a partir da interculturalidade crítica, que ela considera mais eficaz para lidar com questões vinculadas à subordinação.

É necessário que se considere a função da instituição escolar no processo de socialização e, neste contexto, a valorização da participação, para que se estimule o protagonismo infantil. Diferentes sociedades terão diferentes ideais de homens, logo, diversas opções pedagógicas. Vigotski admitiu que desenvolvimento e aprendizagem são processos que não coincidem, que o processo de aprendizagem precede o do desenvolvimento. Ele criou a área de desenvolvimento potencial e defendeu a ideia segundo a qual o desenvolvimento e a aprendizagem, apesar de relacionados, não se produzem de modo simétrico e paralelo. Vigotski afirma que

a criança aprende a realizar uma operação de determinado gênero, mas ao mesmo tempo apodera-se de um princípio estrutural cuja esfera de ampliação é maior do que a da operação de partida. Por conseguinte, ao dar um passo em frente, no campo da aprendizagem, a criança dá dois no campo do desenvolvimento; e por isso aprendizagem e desenvolvimento não são coincidentes (VIGOTSKI, 1991, p. 8).

Vigotski comenta que as matérias escolares têm uma relação específica e dinâmica com o desenvolvimento da criança, e finalmente que a aprendizagem de disciplinas não abarca todo o conceito de educação, pois o processo educacional incorpora a reprodução do ideal de homem projetado pela sociedade. Qual seria o ideal de homem? Embora as representações sobre a infância tenham sido alteradas com o passar dos tempos, como efetivamente isso tem influenciado o cotidiano dos educadores? Em que 
medida os educadores percebem como sendo necessário compatibilizar as novas representações das crianças a um processo educativo tendo por base a seleção de teorias pedagógicas e epistemologias que se coadunem com a infância da atualidade.

OS PROJETOS EDUCATIVOS, EPISTEMOLOGIAS, PERSPECTIVAS DA EDUCAÇÃO INTERCULTURAL

A importância da educação pode ser representada não só a partir do eixo que destaca o desenvolvimento integral do ser humano (perspectiva funcional da educação intercultural); há ainda um segundo eixo que visa à "educação universal, única e diversa para alcançar a igualdade e incorporar plenamente a diversidade" (WALSH, 2009, p. 7) - a educação intercultural, ou seja, uma educação para todos, com processos e aprendizagens interepistêmicos; intercultural no sentido de repensar, refundar e descolonizar o nacional, como propõe Walsh (2009). Neste contexto, cita-se a interculturalidade no seu sentido crítico, que "é uma construção de e a partir das gentes que têm sofrido um histórico de submissão e subalternização" (WALSH, 2009, p. 09). Ela é questionadora dos modelos vigentes, preocupa-se com as exclusões, negação dos direitos ao acesso ao conhecimento, explicita seu interesse pelo ser e saber.

A interculturalidade crítica, ainda de acordo com Walsh, é um "processo, projeto e estratégia que intenta construir relações - de saber, ser, poder e da vida mesma - radicalmente distintas" (2009, p. 11). Trata-se então de um projeto que provoca o questionamento das ausências - de saberes, tempos, diferenças, etc. - e pensa trabalhar a partir "das emergências que se revelam através da ampliação simbólica de pistas ou sinais da experiência mesma, particularmente a dos movimentos sociais" (SANTOS apud WALSH, 2009, p. 12).

Significa que não é suficiente inserir pessoas em programas especiais ou em grupos já consolidados, mas possibilitar sua participação na constituição do próprio grupo e na elaboração dos programas, enfrentando as estruturas rígidas institucionais para reconstruí-las juntos. $O$ enfrentamento da colonialidade teria identidade com a epistemologia freireana, que enfatiza uma nova e crítica leitura do mundo, com base na dialogicidade. Os parâme- 
tros de referência que podem balizar a educação, na perspectiva proposta por Freire, são as experiências existenciais dos educandos (FREIRE, 2014). E os projetos educativos, para serem compatíveis com a pedagogia decolonial, proposta por Walsh, o são também com a epistemologia freireana, pois, na concepção de Walsh, seu suporte são as "discussões e intervenções políticas, sociais, epistêmicas e éticas" (WALSH, 2009, p. 13). E as crianças, onde estariam nisso tudo? No local onde estão os demais seres humanos: na sociedade, na cultura, participando, aprendendo, dialogando, negociando e inovando. Para isso o reconhecimento efetivo do direito à existência e participação das crianças deve ser garantido.

Nesse norte, Candau (2011, p. 333) lembra o efeito nefasto "da base eurocêntrica silenciando ou inviabilizando vozes, cores, crenças e sensibilidades". É ainda Candau (2011, p.342) quem escreve que

a escola tem um papel importante na perspectiva de reconhecer, valorizar e empoderar sujeitos socioculturais subalternizados e negados. E esta tarefa passa por processos de diálogo entre diferentes conhecimentos e saberes, a utilização de pluralidade de linguagens, estratégias pedagógicas e recursos didáticos, a promoção de dispositivos de diferenciação pedagógica e o combate a toda forma de preconceito e discriminação no contexto escolar.

Faria, Macedo e Santos (2013), no texto Educação infantil e diversidade cultural: para uma pedagogia macunaímica, apresentam um conceito de pedagogia como "ciência, arte e técnica, tendo as crianças pequenas como protagonistas, reconhecendo suas especificidades e sua diversidade" (2013, p. 51). As autoras se opõem a uma pedagogia única, escolarizante; defendem o direito à educação mesmo para os de pouca idade, e ressaltam a existência de uma criança real, no presente.

As contribuições ao tema, trazidas no livro Educação Infantil e Diferença, organizado por Abramowicz e Vandeenbroeck (2013), irão enfatizar um olhar especial para as crianças menores na perspectiva da educação intercultural. Nessa obra, as autoras Sandra R. S. Richter e Maria Carmen S. Barbosa escreveram um capítulo: Entre Mia Couto e Michel Vandenbroeck, outra educação da infância por inventar. As autoras defendem a posição segundo a qual é possível "inventar uma pedagogia com pressupostos anti- 
colonialistas que enfrente o modelo convencional e capitalístico de educação das crianças e que valorize as ambiguidades da infância e as complexidades dos processos educacionais" (RICHTER; BARBOSA, 2013, p. 27). Para muito além da escolarização, educar crianças pequenas também implica saber lidar com o imprevisível, com as surpresas, com os sonhos, com a imaginação. $E$ isso tudo num mundo real no qual em cada esquina pode ocorrer um encontro com a diversidade, mas também com algo desagradável, até mesmo violento. Isso leva à consideração das propostas tanto de Mia Couto quanto de Michel Vandenbroeck, que defendem "uma acepção não colonizadora de infância e educação" (2013, p. 29).

Mas em que, para eles, consistiriam os processos anticoloniais? Para início de conversa, seria necessário que as reflexões enfatizassem a alteridade entre o eu e o outro, explicam Richter e Barbosa (2013). E quando o outro é a criança algumas dificuldades se sobressaem, como atestam vários autores. Para Richter e Barbosa, a "dupla face do poder colonial, adulto, branco, eurocêntrico, na busca de uma ação civilizatória, constituiu uma engenharia social para domar os selvagens e educar as crianças" (2013, p. 30). As autoras acreditam que

a educação da infância precisa da poesia, da ficção, de outros referenciais que não sejam endógenos à educação, das teorias que convencionalmente ordenaram a educação, nem das atualmente preponderantes inspiradas apenas no treinamento para o mercado, na competição, na preparação de um futuro $(2013$, p. 32).

É importante salientar as vivências da infância pelas crianças. Tanto Mia Couto quanto Vandenbroeck, cujos pontos de vista são analisados pelas autoras citadas acima, valorizam a questão da identidade como fundamental na educação. E não se deve esquecer que é a linguagem que comunica o pensamento das crianças, seus modos de sentir e perceber o mundo, não se trata de opor oral e escrita mas apoiar uma "pedagogia que considere a oralidade; o tempo e a imaginação, como mediadores para colocar universos em conexão" (2013, p. 47). A partir disso ocorreria, com maior facilidade, o encontro da identidade plural. Assim seria a melhor forma de trabalhar com a diversidade, pensam as autoras mencionadas. 
No que se refere aos aspectos econômicos, educacionais e sociais do respeito à diversidade na educação infantil, é o próprio Vandenbroeck (2013) quem esclarece a postura do pedagogo face à diversidade e igualdade. Para o autor, deve haver uma preocupação permanente que"numa visão abrangente teria como objetivo integrar as perspectivas econômicas, educacional e social, em vez de favorecer apenas um paradigma" (2013, p. 21).

Se a ênfase for dada à diferença, e recorrendo aos denominados filósofos da diferença ou pós-estruturalistas, tais como Michel Foucault e Gilles Deleuze, entende-se que a diferença

abre possibilidades para questionarmos os essencialismos e etnocentrismos tão presentes no campo educacional, para pensarmos nas diferenças baseadas nos hibridismos culturais, deslocando as ordens binárias que hierarquizam o negro/branco, a criança/adulto, o heterossexual/homossexual, o cristão/umbandista, etc. (OLIVEIRA; ABRAMOWICZ, 2013, p. 152).

As autoras sugerem que, no caso de diferença, seja utilizada uma "pedagogia da multidão" que inclua as "diferenças como algo positivo e definidor das relações pessoais" (OLIVEIRA; ABRAMOWICZ, 2013, p. 154). Essa ideia poderia levar à compreensão da infância não só do ponto de vista biológico e psicológico, que a consideram "colonizada pela ideia do adulto", inferior a ele, abrindo espaço para outras representações da infância (2013, p. 154).

Tais autoras usam a expressão "pedagogia da multidão" em substituição à "pedagogia do povo" por considerarem esta como sendo colonizadora. E por quê? Pelo fato de usarem concepção de povo, assentando-se em "universalismos e essencialismos", enquanto o conceito de "multidão" é mais amplo, não apresenta homogeneização nem padronização. A educação para as multidões enfatiza a hibridização e a diferença "a partir de questões que nos propõem uma releitura das temáticas do antirracismo, do feminismo, do multiculturalismo, etc." (OLIVEIRA; ABRAMOWICZ, 2013, p. 160). Nessa acepção, a pedagogia se comprometeria com a produção de um outro diferente e não igual a ninguém. Uma educação para a multidão na educação infantil precisaria visar a essa produção das diferenças, possibilitando às crianças experimentar, saindo do controle, do adestramento, fugindo das noções adulto-criança. Nessa direção, entendem-se as reflexões de Walsh, que focam, 
em especial, a defesa dos povos e culturas ancestrais. Por analogia foram demonstradas, neste artigo, a partir dos mesmos paradigmas, as relações de subalternidade entre crianças e adultos.

\section{ConsideRAÇÕES PARA ESSE TEMPO DE ESTUDO}

Este artigo apresentou algumas contribuições de autores contemporâneos com relação à importância da abordagem da educação intercultural, visando a constituir uma base para a elaboração de projetos educativos focados, sobretudo, na educação infantil. Sabe-se que o assunto não foi esgotado. Mas, apesar disso, algumas questões consideradas fundamentais puderam vir à tona e podem subsidiar reflexões na ocasião em que forem elaborados os projetos educativos.

Em consonância com vários autores que se dedicam à compreensão da infância e à valorização da criança como participante ativa do processo de aprendizagem, desenvolvimento e elaboração cultural, foram lembrados conceitos fundamentais que poderão auxiliar na "decolonialidade"/emancipação da infância. Nesse sentido, o filósofo Renaut (2002) alinha-se com os argumentos apresentados pelos diversos autores citados neste texto, sugerindo que a relação educativa se dê, respeitando os direitos e a ética para que a criança seja considerada como sujeito. Isso irá, necessariamente, afetar as relações entre ela e os adultos, e inclusive servir de base para a elaboração dos projetos educativos que não devem desprezar as condições de participação desse grupo que, embora minoritário, já ocupa uma posição de destaque na sociedade, se forem consideradas as bases teóricas propostas por autores, entre os quais alguns foram aqui mencionados.

Aos pais e aos educadores, de modo geral, o lembrete de que a única forma de hierarquia admissível, aquela que se compatibiliza com a representação atual da infância, é a que é exercida horizontalmente (RENAUT, 2002). Esse seria um dos caminhos por meio do qual se buscaria garantir a libertação da infância face à tendência de subordinação a que permanece, em muitas situações, diante do adulto. Renaut comenta ainda sobre o espaço e o processo de educação: seja familiar ou escolar. Defendendo o ponto de vista segundo o qual as questões da educação estão relacionadas às transformações possíveis 
de serem produzidas na representação da criança à medida que as sociedades são estruturadas não mais sobre valores da tradição e da hierarquia, mas sobre aqueles da liberdade e da igualdade. São estes os valores que devem estar presentes no processo educativo das crianças, podendo possibilitar, inclusive, o seu protagonismo. Educar, então, não deve significar "adestrar", mas negociar, dialogar, o que só pode ocorrer se e quando se olha, escuta e respeita o outro-criança, e muito especialmente, se ele for a criança pequena.

\section{INTERCULTURAL EDUCATION, EPISTEMOLOGIES AND EDUCATIONAL PROJECTS}

AвSTRACT: This article is based on a theoretical review and intends to present some contributions that can be useful in the development of educational projects in the context of intercultural education. The objective is to favor the dialectical integration of people who have differences and belong to different socioeconomic contexts. In this perspective, it is valued the dissemination of knowledge and the "hybridized" epistemology, as well as the political confrontation to modify some power relations in order to promote the "emancipation" of children. This one, supported by a conscious, critical, ethical posture, would culminate in a renewal of relations based on dialogue and on new forms of participation and expression of being, living and knowing childhood that must be present in educational programs.

KEYWORDS: intercultural education. emancipation. educational projects. childhood.

\section{EDUCACIÓN INTERCULTURAL, EPISTEMOLOGÍAS Y PROYECTOS EDUCATIVOS}

RESUMEN: Este artículo, realizado a partir de una revisión teórica, tiene el propósito de presentar algunas contribuciones que pueden ayudar en la elaboración de proyectos educativos desarrollados desde la perspectiva de la educación intercultural. El objetivo es favorecer la integración dialéctica de personas que presentan diferencias y que pertenecen a diferentes contextos socio-económicos. Desde esta perspectiva, se valoran la circulación de saberes y epistemologías "hibridadas", haciéndose necesaria la confrontación política para modificar algunas relaciones de poder, con el objetivo de promover la "emancipación" infantil. Esto, apoyado en una postura conscientecrítico-ética, culminaría con una renovación en las relaciones, basada en el diálogo y en las nuevas formas de participación y expresión del ser, vivir y saber de la infancia, que deben ser contempladas en los proyectos educativos.

Palabras Clave: Educación Intercultural. Emancipación. Proyectos Educativos. 


\section{REFERÊNCIAS}

ABRAMOWICZ, A.; VANDENBROECK, M. (Org.). Educação Infantil e Diferença. Campinas, São Paulo: Papirus Editora, 2013.

BONDIOLI, S.; BECCHI, E. Avaliando a pré-escola: uma trajetória de formação de professores. Campinas, São Paulo: Autores Associados, 1994.

BROUGÈRE, G.; ULMANN, A. Perguntas a Bárbara Rogoff, professora da Universidade da Califórnia, Santa Cruz. In: (Org.). Aprender pela vida cotidiana. Tradução de Antonio Pádua Danesi. Campinas, SP: Autores associados, 2012. p. 318-320.

BUSSOLETTI, D.; MOLON, S. I. Diálogos pela alteridade: Bakhtin, Benjamin e Vygotsky. Cadernos de Educação, Pelotas, v. 37, p. 69-91, set./dez. 2010.

CANCLINI, N. G. A globalização Imaginada. São Paulo: Iluminuras Ltda., 2003.

Culturas híbridas; estratégias para entrar e sair da modernidade. 2. ed. São Paulo: Editora da Universidade de São Paulo,1998.

CANDAU, V. M. Diferenças culturais, Cotidiano Escolar e Práticas Pedagógicas. Revista Currículo sem fronteiras, v. 11, n. 2, p. 240-255, jul./dez. 2011.

COPPETE, M. C. Educação para a diversidade numa perspectiva intercultural. Revista Pedagógica, ano 15, n. 28, v. 1, p. 231-262, jan./jun. 2012.

.; FLEURI, R. M.; STOLTZ, T. Educação para a diversidade numa perspectiva intercultural. Revista Pedagógica, ano 15, n. 28, v. 1, p. 341-345, jan./jun. 2012.

EDUARDS, C. Parceiro, promotor do crescimento e guia - Os papéis dos professores de Reggio em ação. In: ; GANDINI, L.; FORMAN, G. As cem linguagens da criança; a abordagem de Reggio Emilia na educação da primeira infância. Porto Alegre: Editora Artes Médicas, 1999. p. 159-176.

FALTERI, P. Interculturalismo e culturas no plural. In: FLEURI, R. M. (Org.). Intercultura e movimentos sociais. Florianópolis: UFSC-MOVER/NUP, 1998. p. 33-44.

FARIA, A. L. G.; MACEDO, E. E.; SANTOS, S. E. Educação infantil e diversidade cultural: para uma pedagogia macunaímica. In: ABRAMOWICZ, A.; VANDENBROECK, M. (Org.). Educação infantil e diferença. Campinas, S.P.: Papirus, 2013. p. 49-70.

FLEURI, R. M.; COPPETE, M. C.; AZIBEIRO, N. In: OLIVEIRA, L. B. et al. (Org.). Culturas e Diversidades Religiosas na América Latina. Pesquisas e diversidade religiosa na América Latina. Pesquisas e perspectivas pedagógicas. Blumenau: Ed.Edifurb, 2009. p. 36-46.

FREIRE, P. Pedagogia do oprimido. Rio de Janeiro/São Paulo: Paz e Terra, 2014.

MIALARET, G. Ciências da Educação: aspectos históricos, problemas epistemológicos. Tradução de Eduardo Brandão Coleção Biblioteca Pedagógica. São Paulo: Martins Fontes, 2013. 
MOLLO-BOUVIER, S. La sociologia de l'enfance: des premiers pas à la crise de croissance. In: SIROTA, R. Élements pour une sociologie de l'enfance. Rennes: PUR, 2006. p. 37-40.

MONTANDON, C. L'Éducation du point de vue des enfants. Paris/Montreal: L'Harmattan, 1997.

OLIVEIRA, F.; ABRAMOWICZ, A. Educação e diferença na direção da multidão. In: Educação infantil e diversidade cultural: para uma pedagogia macunaímica. In: ABRAMOWICZ, A.; VANDENBROECK, M. (Org.). Educação infantil e diferença. Campinas, S.P.: Papirus, 2013. p. 149-168.

OTTAVI, D. Le milieu de l'enfant, facteur d'éducation. In: SIROTA, R. Élements pour une sociologie de l'enfance. Rennes: PUR, 2006. p. 103-114.

RENAUT, A. La liberation des enfants: contribution philosophique à une histoire de l'enfance. France: Calmann-Lévy Bayard, 2002.

RICHTER, S. R. S; BARBOSA, M. C. Entre Mia Couto e Michel Vandenbroeck: Outra educação da infância por inventar. In: ABRAMOWICZ, A.; VANDENBROECK, M. (Org.). Educação Infantil e diferença. Campinas, São Paulo: Campinas: Papirus, 2013. p. 27-48.

SANTOS, B. S. Uma concepção multicultural dos direitos humanos. Lua Nova, n. 39, p. 105-124, 1997.

$\therefore$ MENESES, M. P. (Org.). Epistemologias do Sul. São Paulo: Cortez, 2010.

VIGOTSKI, L. S. A formação social da mente: o desenvolvimento dos processos psicológicos superiores. 4. ed. São Paulo: Martins Fontes, 1991.

WALSH, C. Interculturalidad y (de) colonialidad: perspectivas críticas e políticas. In: CONGRESSO DA ASSOCIATION POUR LA RECHERCHE INTERCULTURELE (ARIC) 2009. Florianópolis, UFSC. Anais eletrônicos... Disponível em: <http://aric.edugraf.ufsc.br/ congrio/anais/artigo/767/textoCompleto>. Acesso em: 15 out. 2014.

VERA LÚCIA CHACON VALENÇA: Doutora em Psychologie Appliquée pela Université Réne Descartes-Paris $V$. Pós-doutora no Instituto CNRS, de Roma. Professora aposentada da Universidade Federal de Santa Catarina (UFSC) e atualmente docente do Programa de Pós- Graduação em Educação da Universidade do Sul de Santa Catarina (Unisul), onde ministra a disciplina Educação e cultura da Infância e desenvolve pesquisas para implantar o Museu das Crianças do Brasil projeto de sua autoria.

E-mail:veravalenca@uol.com.br 
LUCIANE PANDINI SIMIANO: Doutora em Educação pela Universidade Federal do Rio Grande do Sul (UFRGS). Atualmente é professora do quadro permanente do Programa de Pós-Graduação em Educação da Universidade do Sul de Santa Catarina (Unisul). Tem experiência na área de educação, com ênfase em educação infantil, atuando principalmente nos seguintes temas: educação de bebês, pesquisa com crianças, linguagem, cotidiano e organização dos espaços e tempos, brincadeira e formação de professores.

E-mail: luciane.simiano@unisul.br

AMANDA DA SILVA MENGER: Mestre em Educação pela Universidade do Sul de Santa Catarina (Unisul). Atualmente trabalha no Departamento de Comunicação da Prefeitura de Tubarão (SC).

E-mail: amandamenger@gamial.com 